\title{
Energy Expenditures of Gateball and Tai Chi Chuan 門球及太極運動的能量消耗
}

\author{
Pinky TSO Lena FUNG \\ Department of Physical Education, \\ Hong Kong Baptist University, HONG KONG
}

曹碧珠溤䔎娜

香港浸會大學體育學系

\begin{abstract}
Gateball originates in Japan and is particularly popular among elderly persons (Traphagan, 1998). The game, played very much like croquet but on a faster clip, was introduced to Hong Kong in 1986. Almost twenty years later, the game has grown in popularity and is now played by over 800 elderly persons on a regular basis (Ms. Michelle Ma, personal communication, 5 August 2005). While Gateball is appreciated as a team game, Tai Chi Chuan, another activity popularly pursued by elderly persons in Hong Kong, is appreciated predominantly as a solo activity. Research surrounding Tai Chi Chuan far exceeds that of Gateball, therefore, the purpose of this study was to contrast the energy expended in playing Gateball and in Tai Chi Chuan practice. Such insight could be profitably used by recreation providers when planning exercise programs and when promoting activity among the elderly.
\end{abstract}

Key words: Gateball, Tai Chi Chuan, Energy Requirement

\section{摘 要}

門球起源於日本, 是長者喜愛的運動 (Traphagan, 1998)。此運動的規則與随球大致相同。但比槌球的節奏快。門球於 1986 年 引入香港。經過近二十年才普遍在香港流行。現時有大概 800 多名長者定期參與門球運動(Ms. Michelle Ma, 私人通訊，2005)。除 了這項團體運動, 香港的長者亦積極參與太極拳, 一項以個人為主的活動。關於太極拳的研究遠超門球, 因此休閒活動提供者將可在 策劃及推動長者運動時, 有效地利用此研究的結果。

關鍵詞彙：門球, 太極拳, 需用能量。

\section{Introduction}

Regular participation in physical activity is widely accepted as important for health. In Hong Kong, two activities popularly participated by elderly are Gateball and Tai Chi Chuan. Gateball originates in Japan and has grown in popularity among several Asian countries such as Korea, Singapore, and China. It is a game played by two teams with five players in each team. The purpose of the game is for players of the same team to hit their own balls through "gates" while preventing players of opposing teams from doing the same. Therefore, strategic thinking has been said to be an important aspect of the game (Traphagan, 1998). In addition to viewing the game as a means for maintaining a sharp mind, players also see the court as a place for social interaction (Kalab, 1992).

By nature, Gateball is not a strenuous game. It does not require much walking and the batting is performed in a slow and gentle motion. However, when asked why they play Gateball, they would unfailingly respond that it keeps 
them in good physical and mental shape (Kalab, 1992). Given that research documented Gateball as having a multitude of benefits, the purpose of this study was to examine the level of energy expenditure involved in playing the game and to contrast it with that required for a similar duration of Tai Chi Chuan. Previous research on the energy expenditure of Tai Chi Chuan provided evidence of 4-5 METS (Brown et al., 1989; Schneider \& Leung, 1991), thus it would be of interest to confirm this finding and to further contrast it with another activity which is different in nature but gaining popularity among the elderly people in Hong Kong.

Methods of assessing energy requirement of an activity can fall into two main categories, the first being the laboratory method and the other the field method (Tritschler, 2000). The relative merits of either method had been discussed extensively by Dale, Welk, \& Matthews (2002) and therefore would not be repeated here. For this study, an activity monitor was used for collecting data. This approach has been successfully used in previous research where interest is to assess energy requirements in free-moving situations. For example, one model of activity monitor, the Tritrac-R3D, was used by Arnett (2001) to assess the level of energy expended by students in physical education classes and another model of physical activity monitor, the Biotrainer Pro, was used by Andersen, Wadden, Bartlett, Zemel, Verde, \& Franckowiak (1999) in their study of energy demands associated various activities and its effect on weight reduction in obese women. More recently, readings from the CSA activity monitor were used by Pate, Ross, Dowda, Trost and Sirad (2003) as a criterion measure to validate activity level extracted from a self-reporting questionnaire. As could be seen from above review, there are several models of activity monitors. Given the diversity of models available in the market, validation of these instruments as accurate tools for assessing energy expenditure became another strand of important research. Recent findings suggest that the Biotrainer Pro, CSA, and the Tritrac provide good estimates of energy expenditure (Garcia, Langenthal, Angulo-Barroso, \& Gross, 2004; Welk, Almeida, \& Morss, 2003: Welk, Blair, Wood, Jones, \& Thompson, 2000). For this study, the Biotrainer Pro was used as a measuring instrument.

\section{Method}

\section{Participants}

Participants who volunteered for the study were 54 male and 67 female regular Gateball players or Tai Chi Chuan practitioners. To qualify as participants, the individual would need to have been engaged in the activity on a regular basis for at least one year. All participants were recruited through the Tai Chi Association of Hong Kong and the Hong Kong Gateball Association.

The mean age of the participants was $65(\mathrm{SD}=9.24)$ and the age range was between 43 and 85 . Seventy-four were Gateball players and 47 were Tai Chi Chuan practitioners.

\section{Instrument}

The instrument used for collecting data was the Biotrainer Pro activity monitor. This monitor provided two sensitivity options for selection. For vigorous movements, the low-sensitivity option was recommended and for gentle activities, the highsensitivity option was recommended. For this study the latter option was selected.

In selecting data output, calorie was selected. Following the instruction from the manual, the weight of each individual was also entered. By attending to this procedure, the calorie data collected would exclude the individual's metabolic data.

As a standardization procedure, the device, after being initialized, was secured to the right side of the participant's body by means of a belt clip. The point at which the instrument was attached tightly against the body was at the waist, in the frontal plane, and in line with the femur when standing erect.

\section{Data Collection}

Data collection of Gateball players took place in the Gateball court during their regular weekend league plays whereas data of Tai Chi Chuan practitioners took place in an outdoor environment and during their regular practice times. In capturing data, the Biotrainer Pro is set to record data every 15 seconds for the duration of a 30-minute game in the case of Gateball, and in the case of Tai Chi Chuan, recording was made over the entire sequence of Tai Chi Chuan from beginning to end. As Tai Chi Chuan is practiced on a self-monitory fashion, the duration of the sequence ranged from 10 to 15 minutes. In order to standardize the activity level value for calculation of energy requirement and comparison, the activity level per minute for the Gateball and the Tai Chi Chuan was obtained. Therefore, the calorie required would be expressed as calorie expended per minute. 


\section{Resullts}

As the purpose of the study was to compare the energy requirement of two different activities and that the duration of each activity is not the same, the energy requirement per minute of activity was used as a standardized unit for comparison. It was found that the mean energy requirement per minute for Gateball activity is $0.71 \mathrm{cal} /$ minute $(\mathrm{SD}=.47)$ whereas the mean energy requirement per minute for Tai Chi Chuan is $0.31 \mathrm{cal} /$ minute $(\mathrm{SD}=.15)$. To contrast the energy requirement of the two activities, the independent t-test was applied. A significant $t$ ratio $(t=5.54, d f=119, p<.01)$ was obtained. This suggested that the energy requirement for playing Gateball is greater than for practicing Tai Chi Chuan.

\section{Conclusion}

The energy expenditure per minute of two popular activities pursued by the elderly in Hong Kong was examined. The Biotrainer Pro, an activity monitor, was used to measure the energy expenditure of Gateball and Tai Chi Chuan. It was found that the level of energy expenditure per minute involved in playing Gateball is significantly higher than in practicing Tai Chi Chuan.

When practicing Tai Chi Chuan, an individual is engaged in continuous arm and leg movements or weight transfers once the practice begins, and the motion, although very subtle at times, will not cease until the movement series is completed. On the contrary, for a 30-minute game time of Gateball, even though the players need to walk on and off court after each hit, there are also moments in which an individual can stand motionless while waiting to play or while pondering about a strategic move. Despite this movement pattern, the energy requirement of Tai Chi Chuan is found to be less than Gateball playing. How can this be the case when we see Tai Chi Chuan practitioners often sweating and flushed in the face after their practice? In trying to explain this, the authors are of the view that the Biotrainer Pro might not have adequately captured the efforts involved in executing sustained and often eccentric movements essential in practicing Tai Chi Chuan and thus their energy expenditure might not have been fully reflected. If this is the case, might this also be a limitation of the Biotrainer Pro? Future research is needed to validate the use of this instrument on assessing energy expenditure of activities where isometric and eccentric contractions are dominant.
In conclusion, the authors are of the view that the energy expenditure recorded for gateball playing and practicing Tai Chi Chuan is on the low side and suggest that, in order to be involved in a more comprehensive exercise program, both Gateball players and Tai Chi Chuan practitioners should consider engaging in additional forms of exercise, such as walking and stretching, prior to or after their main activity sessions.

\section{References}

Andersen, R.F., Wadden, T.A., Bartlett, S.J., Zemel, B., Verde, T.J., \& Franckowiak, S.C. (1999). Effects of lifestyle activity versus structured aerobic exercise in obese women. Journal of American Medical Association, 281, 335-340.

Arnett, M.G. (2001). The effect of sport-based education lessons on physical activity. Physical Educator, 58, 158-168.

Brown, D.D., Mucci, W.G., Hetzler, R.K., Knowlton, R.G. (1989). Cardiovascular and ventilatory responses during formalized Tai Chi Chuan exercise. Research Quarterly in Exercise and Sport, 60, 246-250.

Dale, D., Welk, G.J., \& Matthews, C.E. (2002). Methods for assessing physical activity and challenges for research. In G.J. Welk (Ed.), Physical activity assessment for healthrelated research (pp. 19-34). Champaign, IL: Human Kinetics.

Garcia, A.W., Langenthal, C.R., Angulo-Barroso, R.M., \& Gross, M.M. (2004). A comparison of accelerometers for predicting energy expenditure and vertical ground reaction force in school-age children. Measurement in Physical Education \& Exercise Science, 8, 119-145.

Kalab, K.A. (1992). Playing gateball: a game of the Japanese elderly. Journal of Aging Studies (Greenwich, Conn.), $6(1), 23-40$.

Pate, R.R., Ross, R., Dowda, M., Trost, S.G., and Sirad, J. R. (2003). Validation of a 3-day physical activity recall instrument in female youth. Pediatric Exercise Science, 15, 257-265.

Schneider, D., \& Leung, R. (1991). Metabolic and cardiorespiratory responses to the performances of Wing Chun and Tai Chi Chuan exercise. International Journal of Sports Medicine, 12, 319-323. 
Traphagan, J.W. (1998). Reasons for gateball participation among older Japanese. Journal of Cross-Cultural Gerontology, 13, 159-175.

Tritschler, K. (2000). Barrow \& McGee's practical measurement and assessment (5th ed.). NY: Lippincott Williams \& Wilkins.

Welk, G.J., Almeida, J., \& Morss, G. (2003). Laboratory calibration and validation of the Biotrainer and Actitrac activity monitors. Medicine and Science in Sports and Exercise, 35, 1057-1064.

Welk, G.J., Blair, S.N., Wood, K., Jones, S., \& Thompson, R.W. (2000). A comparative evaluation of three accelerometry-based physical activity monitors. Medicine and Science in Sport and Exercise, 32, S489-S497.

\section{Acknowledgement}

This research was supported by funding from the Faculty Research Grant of the Hong Kong Baptist University.

\section{Correspondence:}

Pinky Tso, MSc

Department of Physical Education

Hong Kong Baptist University

Renfrew Road

Hong Kong

Email: 04416341@hkbu.edu.hk

Lena Fung, $\mathrm{PhD}$

Department of Physical Education

Hong Kong Baptist University

Renfrew Road

Hong Kong

Email: lenaf@hkbu.edu.hk 